\title{
Effects of Electronic-Book Reading on Adult English Learners' Higher-Order Thinking and Self-Efficacy
}

\author{
Min-Hsun Chiang \\ Department of Foreign Languages and Literature \\ Tunghai University \\ Taiwan R.O.C
}

\begin{abstract}
Electronic reading has become an integral part of our daily life. Nowadays, we read more from our digital devices than print-based materials. However, most reading assignments inside the university classrooms remain print-based. Therefore, integrating electronic reading with the existing literacy instruction meets the changing needs of our adult English learners. The possibility that the younger generation growing up in a digital environment may lack the ability and confidence to read deeply concerns many educators. This mixed-method study aims to explore the effects of Kindlemediated reading on university students' higher-order thinking and reading self-efficacy. Quantitative and qualitative data were collected from 45 first-year students taking their year-long required reading course. The analyses of the post-reading questions raised by the participants indicate that the Kindle group raised a higher number of higherorder thinking questions than did the hard-copy group. However, no significant difference was identified in reading self-efficacy between the two groups.
\end{abstract}

Keywords: English as Foreign Language (EFL), Electronic Reader,Kindle Reader, Self-Efficacy in Reading, Critical Thinking, Higher-Order Thinking Questions

\section{Introduction}

How to engage the younger generation in meaningful classroom learning has become a universal concern for many educators. Being surrounded by infinite technical opportunities since their upbringing, the members of the younger generation grew up using the Internet, which made social media an integral part of their daily life. Despite all the promising prospects brought upon by the continually changing social media, educators are concerned about the natural and rapid access to information might be detrimental to the younger generation's independent and critical thinking skills. Scheja (2006) explains the notion of "delayed understanding," which describes the complications of a situation where lack of time to reflect on learning material obstructs students' understanding of course material. Scheja (2006) points out that time to reflect on previous experiences are essential to the deep understanding of learning materials. Teachers and educators were urged to explicitly "support new modes of reading, writing and communicating, integrating discovery, searches, navigation and the appropriateness of diverse resource" (Brabazon, 2007, p. 39). That is, developing students' critical thinking skills remains crucial. Many students, particularly in Asia, come to universities without prior schooling experiences that encourage or require critical thinking and reading. Nevertheless, in today's technology-laden era, workplaces and universities everywhere expect and demand workers and students to be proficient in critical thinking as well as in identifying and solving problems. Since long, it has recognized that critical thinking and reading skills constitute a core for successful university experience for all students. However, most students today are not yet competent critical readers of academic and electronic texts, which is especially true of adult EFL students. The current study represents the quest to discover a way to motivate the younger generation English learners to read critically and develop self-efficacy as they engage in EFL reading. With the advent in ICT, many electronic reading devices, such as Kindle, feature multimodal functionalities, such as audio, video, hyperlinks, and interactive tools. These interactive tools allow readers to interact with the text via inserting/deleting/replacing text; marking passages by underlining/highlighting; adding comments by attaching files/appending notes, and manipulating the text formatting on the screen page. The dynamic nature of the hypertext environment gives it an ability to find common ground with the readers who are constantly staying on a loop of texting, Instagramming, and Facebooking. Consequently, the hypertext environment may enhance the younger generation's engagement in electronic reading, which may help cultivate their reading self-efficacy. This study intends to answer the following two research questions: 1) Are there any differences in the students' higher-order thinking skills, measured by the number of higher-order thinking questions raised, between the Kindle group and the hardcopy group as the year-long reading program unfolds? 2) Is there any difference in the students' self-efficacy in reading between those who use Kindle and those who use Hard copy? 


\section{Review of Related Literature}

\subsection{Electronic Reading via Hypertext}

There has been a growing interest in investigating how hypertext affects the reading. Charney (1994) argued that the advent of hypertext is a new and exciting development that has far-fetching implications for researchers and teachers in English. Hypertext has the potential to change the way people process information. As a result, many studies have explored the role hypertext plays in language learners' reading processes and how hypertext can benefit language learners. Hypertext differs in one of the most vital elements of printed text: its linear structure. Hypertext more closely resembles the net-worked associating organization of information in human memory. Some language learners might benefit from the non-linear structure of hypertext, whereas others find the non-linear nature of hypertext disturbing. Many reading theorists argue that readers rely on the linear structure to formulate generalized patterns, called schemas. Hypertext violates the standard assumptions of what texts are to be presented. Readers traditionally rely on the writer to select topics, determine their sequence, and signal relationships among them by employing conventional discourse cues. However, previous studies argue that the hypertext systems provide readers much greater control over the information they read and the sequence in which they read it (Charney, 1994; Jong \& Hulst, 2002; Shapiro, 2004). When the readers have greater control of information, they also bear a greater burden as they must search for the information they need to relate it to other facts in the network, (Charney, 1994). Therefore, with the chance to control what to read, students might become active learners (Landow, 1992). Lodewijks (1982) posited that some students might learn more effectively when they can choose their reading order rather than following the sequences dictated by the author. Furthermore, self-regulation prompts readers to adopt more active reading strategies, which is prerequisite to critical thinking. In the present study, the researcher will choose Kindle Reader as a tool to investigate the impacts hypertext reading will bring on higher-order thinking and reading self-efficacy.

\subsection{Teaching Critical Thinking to ESL/EFL Students}

Before the 1990s, teaching critical thinking became popular and had been widely implemented in many university courses, particularly in western institutions, such as the United States and Canada. There is no single best approach for teaching critical thinking. Brown's (1997) used debates as a means for sharpening students' thinking skills while Patterson (1993) used children's books to promote critical thinking skills among the fourth-grade students in a rural elementary school. MacKnight (2000) taught critical thinking through online discussions at the University of Massachusetts. Critical thinking skills are often integrated with the subject area curriculum, especially at the college level. Students will not be able to practice critical thinking unless they are given specific instructions related to their subject field. Integrating the teaching of critical thinking with a particular subject area is one of the effective ways to develop students' abilities to transfer and apply thinking skills to similar subjects outside of school (Patrick, 1986; Kassem, 2005; Tillman, 1994).

This trend has also influenced second/foreign language teaching and learning worldwide (Day, 2003; Long, 2000). Critical thinking made its first presence in composition course as it was integrated with ESL/EFL curriculum. Critical thinking subsequently became an integral part of ESL and EFL reading courses (Day, 2003). Nevertheless, there are some arguments against the integration of critical thinking into ESL/EFL classrooms. For instance, Atkinson (1997) argued that critical thinking is inappropriate for ESL/EFL students and should be extremely cautious when incorporating it into ESL/EFL instruction. Atkinson believed that critical thinking is, in fact, a "social practice" that represents western cultures and values affiliated with English speaking nations. He further explained that critical thinking is "cultural thinking;" therefore, it is difficult for ESL/EFL students to understand. To the contrary, Davidson (1998) contended that critical thinking should be taught to ESL/EFL students because one of the goals of language teaching is to help students communicate or interact with native speakers of English. In many English-speaking classrooms, particularly at the college level, students need the ability to critique, argue, predict, comment, and express one's own opinion. Davidson (1998), therefore, believed that ESL/EFL teachers have the responsibility to introduce critical thinking to ESL/EFL students, especially those who plan to enter higher education in English speaking countries. Furthermore, Davidson and Dunham (1996) conducted a pilot study using a "commercially available critical thinking essay test" to assess the effects of teaching critical thinking (p.122). They found that the students in the treatment group with the critical thinking-imbedded ESL instruction performed significantly better than those in the control group receiving only the traditional intensive English instruction. Besides, several researchers pointed out that ESL/EFL students' critical thinking skills can be fostered if they were provided with suitable projects or activities and sufficient time to give and receive comments from one another (Browning, Halvorsen, \& Ahlquist, 1996; Kamada, 1996; Long, 2000). 


\subsection{Self-Efficacy}

The learner's belief of whether he/she is capable of accomplishing a learning task has profound effects on learner's goal setting, effort investing, and perseverance exerting (Bandura, 1994). Bandura (1991) proposed a model of reciprocal causation in which human functioning is viewed as the product of a dynamic interplay of personal, behavioral, and environmental influences. Bandura contends that people act and behave based on how they think, believe, and feel, and their environment shapes their thinking. A learner's self-efficacy may be impacted by learner control. As aforementioned, hypertext could provide EFL readers greater control over the information and the sequence they are about to read in. Hypertext grants learners more flexibility and individuality to access information. In other words, electronic reading provides learner greater degree of learner control. Merrill (1984) divided learner control into four types: (1) control of pace, (2) content control, (3) display control, and (4) control of internal processing. Control of pace allows learners to decide the speed of reading. Content-control permits students to decide how much they can absorb. Display control allows learners to determine the level of difficulty. Finally, control of internal processing helps learners take advantage of cognitive strategies and metacognition. For example, learners could either paraphrase what they have read or repeated reading the novel. Moreover, Shapiro pointed out that traditional readers assumed their reading had been arranged while a hypertext reader might change the sequence. In other words, there is a greater extent of learner control in hypertext reading. The current study attempts to investigate if electronic reading will also cultivate EFL learners' self-efficacy via enhanced reader control.

\section{Methodology}

\subsection{Participants and Setting}

As a result of convenient sampling, forty-five English-major first-year students were recruited from two intact Guided Reading classes to participate in this study. Based on the department student profile, the participants' average English proficiency was at the intermediated level, as measured by the General English Proficiency Test (GEPT). The class meets two hours per week to engage in intensive and extensive reading. To make sure there was no significance in their English reading comprehension between the two classes, the reading comprehension test was administrated to the students on the outset of the study. The results indicated that there was no significant difference between the two classes. A pre-study survey found that none of the participants had experience using Kindle to read previously.

\subsection{Implementation of the Present Study}

Participants were randomly assigned to the kindle group and the hard-copy group. The kindle group was given two tutorials on how to use the Kindle Reader and its various features during the first two weeks of the study. After grouping students and making sure that they were at the same baseline on the onset of the study, participants in both groups were assigned the same five novels to read by following the same instructor and the same syllabus. After finishing their scheduled reading assignments, the participants were required to raise 4 to 5 questions per assignment for book discussions.

\subsection{Data Collection}

The data were collected from three primary sources, including the post-reading questions raised by the participants, participants' responses to the self-efficacy scale (Appendix A) and their responses to the open-ended questions. The reading-related self-efficacy scale was piloted with other adult EFL learners, and a satisfactory reliability coefficient was secured at .86 . Both groups were required to raise 4 to 5 questions based on the novel chapters they just finished reading. Participants in both groups were asked to fill in a self-efficacy scale at the end of the semester. Besides selfefficacy questionnaire, to enhance the reliability of the numeric data, an open-ended survey was given to the participants at the end of the study.

\subsection{Data Analysis}

All of the questions raised by the participants and the responses to the self-efficacy scale were analyzed quantitatively and qualitatively. To answer the first research question regarding higher-order thinking, the discussion questions raised by the participants were analyzed and categorized by referring to Bloom's Taxonomy. Table 3 provides an example of how the post-reading questions were analyzed and categorized. 
Table 1.Examples of Higher-Order Thinking Questions via Bloom's Taxonomy

\begin{tabular}{|l|l|l|}
\hline Level & & Example \\
\hline Level 1 & Knowledge & What was Mr. Penderwick's favorite saying? \\
\hline Level 2 & Comprehension & What is the main idea of this chapter? \\
\hline Level 3 & Application & If you were Bud, how would you response to Ma'am? \\
\hline Level 4 & Analysis & Why does Bud need to stand in line? \\
\hline Level 5 & Synthesis & How would your life be different if you were sent to a military school? \\
\hline Level 6 & Evaluation & Why do you think Penderwickis so kind? \\
\hline
\end{tabular}

The categorized results were tabulated to show the differences between the Kindle and the hard copy groups and the occurrences of six-level questions over a course of 3 months. To answer the second research question, an independent sample t-test was computed through SPSS 23.0 with the significance level set at $\mathrm{p}<.05$ to see whether there wasany significant difference in the students' self-efficacy in reading.In addition to the numeric analyses, participants' responses to the open-ended survey were content analyzed to identity any emerging themes regarding the integration of Kindle, critical thinking via electronic reading and reading self-efficacy.

\section{Results and Discussions}

The tentative answers to the research questions will be presented below as the research results. Two major findings will be discussed concerning the prior research. First, this study identified the positive effects of Kindle-mediated electronic reading on critical thinking as reflected by the higher number of higher-order thinking questions raised by the Kindle group. Second, there was no significant difference in reading-related self-efficacy between the two groups at the end of the current study.

\subsection{The Kindle group raised more higher-order ( 3 and above) thinking questions than the hard copy group did.}

Questions raised based on the book chapter reading were collected from each participant from March to May to investigate if there are any differences in critical thinking ability between those who read from Kindle and those who from Hard copy. To gauge the extent of critical thinking, all the questions raised were analyzed and categorized from level 1 to 6, according to the cognitive domain of Bloom's Taxonomy. Figure 1 displays the total number of questions that were raised for each level from two groups. As indicated, the number of level 1 to 3 questions raised by the hard copy group is more than that by the Kindle group. On the contrary, the number of level 4 to level 6 questions raised by the Kindle group is twice greater than that of the hard copy group.

Figure 1. Total Number of Questions Raised by Level from the Two Groups

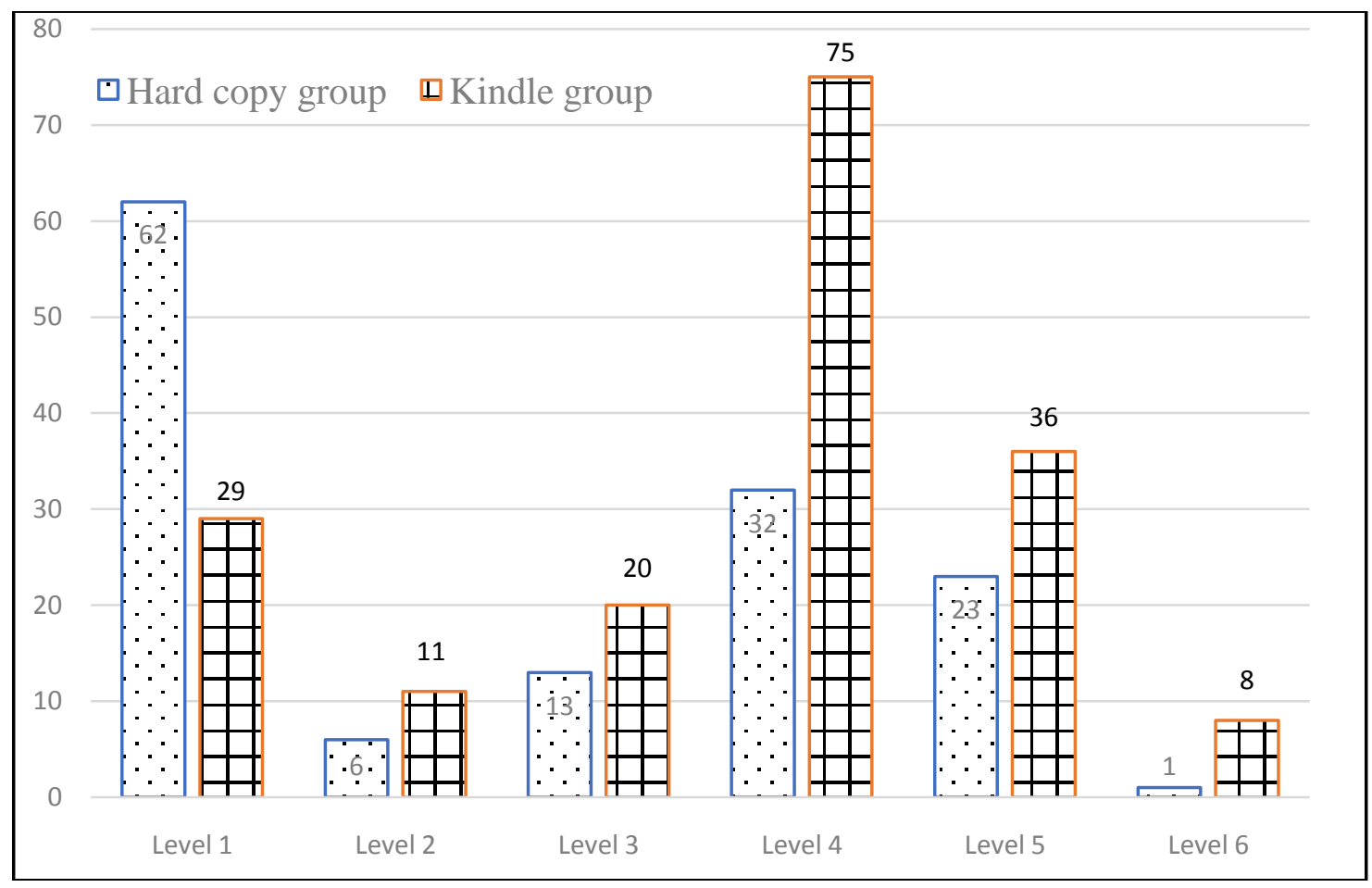


Figure 2 displays the total number of questions raised for each level by the hard copy group after one semester. By the end of the study, the number of questions from level 1 to level 3 was increased while the number of level 4 to 6 questions, indicating high-order thinking, was decreased. For the hard copy group, level 1 has the greatest improvement of all. Figure 3 shows the opposite pattern with the kindle group. For the kindle group, the number of questions from level to 3 was decreased; yet, the number of questions from level 4 to 6 was increased. This finding suggests the potentially positive influence of electronic reading on cultivating critical thinking ability.

Figure 2.Total Number of Questions Raised for Each Level by Hard Copy Group

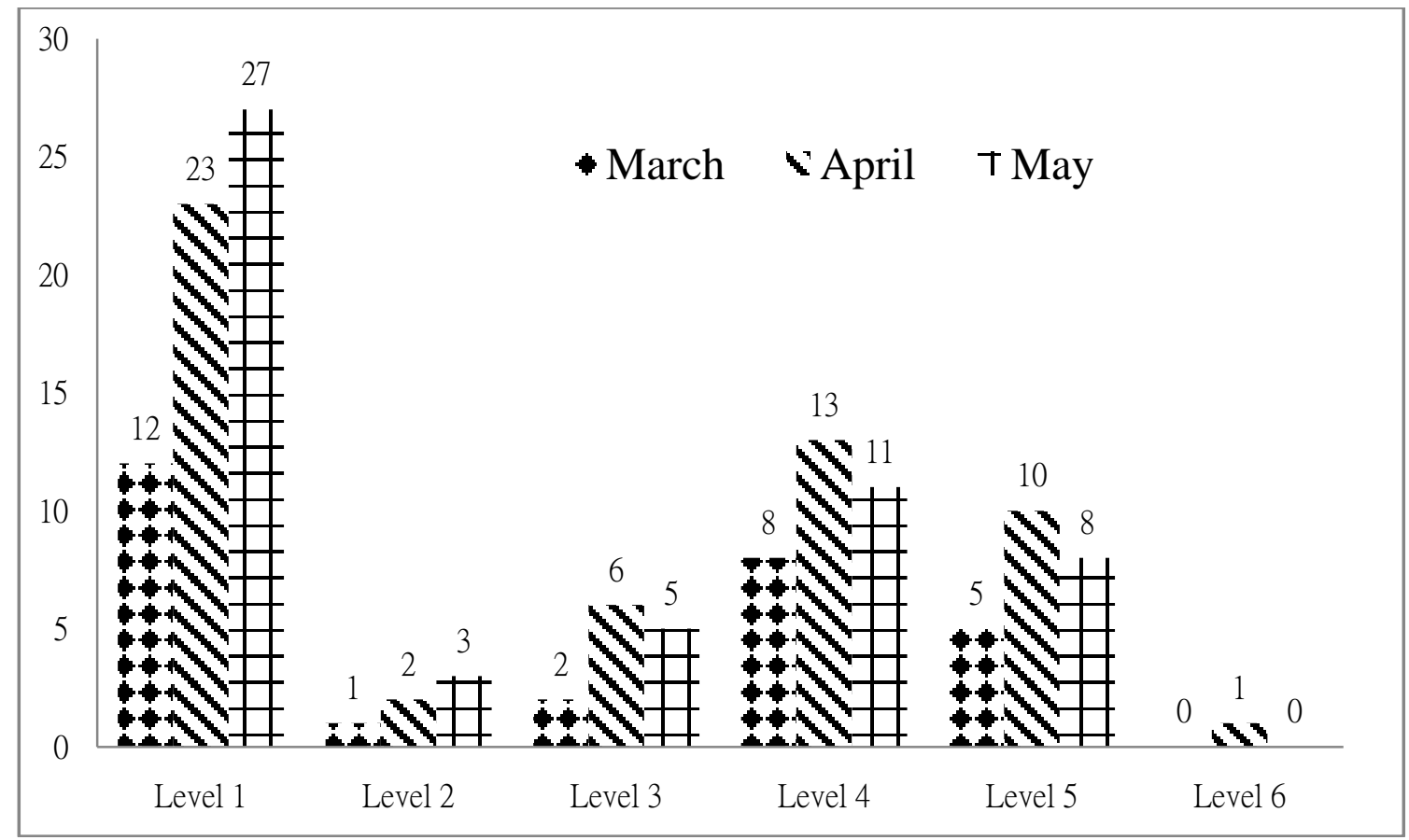

Figure 3.Total Number of Questions Raised for Each Level bythe Kindle Group

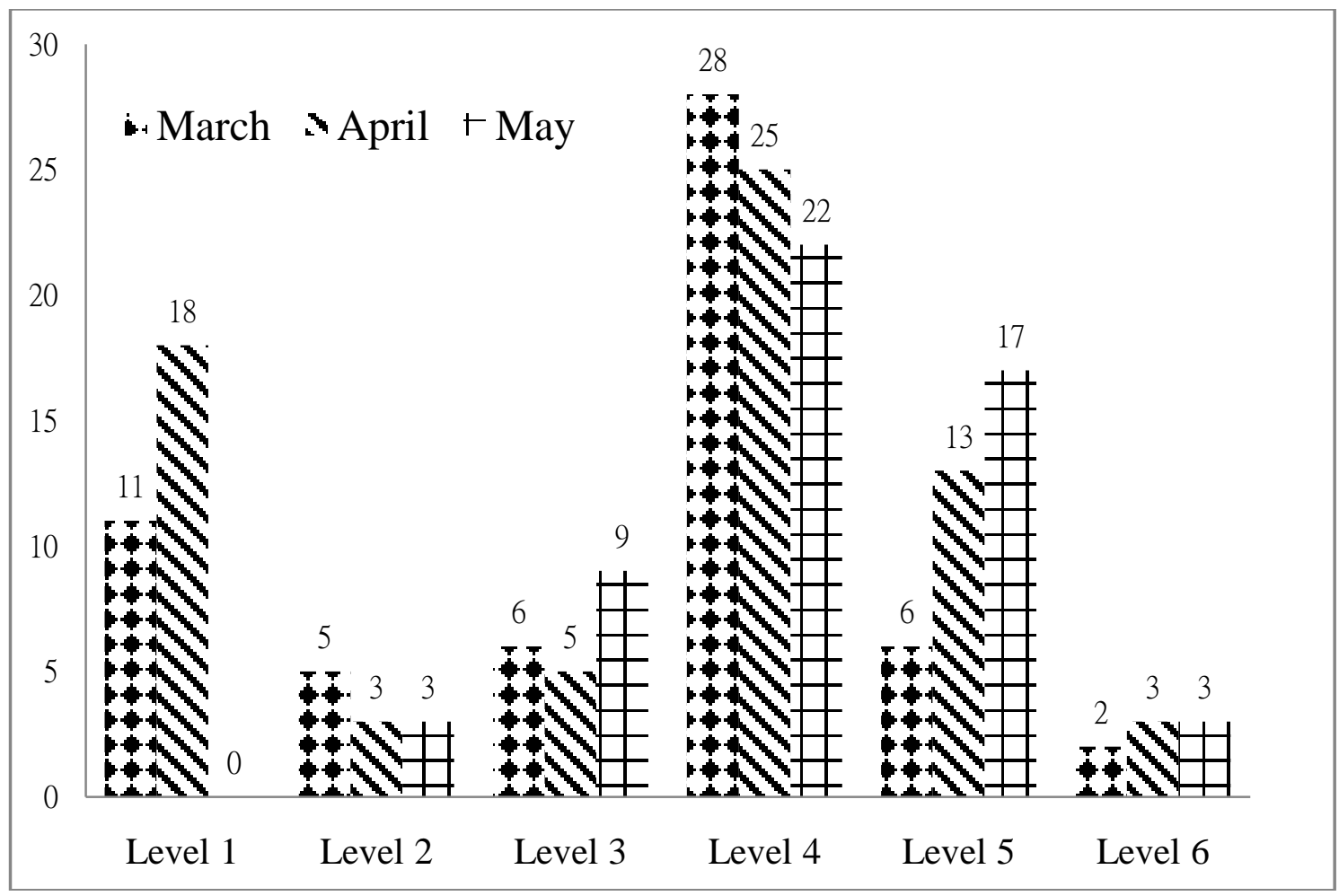


During the 5-month course of this project, participants in both groups raised 4-5 questions per reading assignment. The following two charts provide samples of two randomly picked participants' frequency of raising level 1 to 6 questions from both groups. Sample questions raised by the participants were marked with the corresponding level. Rose, from the hard copy group, raised many lower-level questions. Julian, from the Kindle group, successfully raised many higher-order thinking questions during the course of this study, indicating her critical thinking skill was cultivated.

\section{Chart1. Sample Questions Raised by Rosefrom the Hard Copy Group}

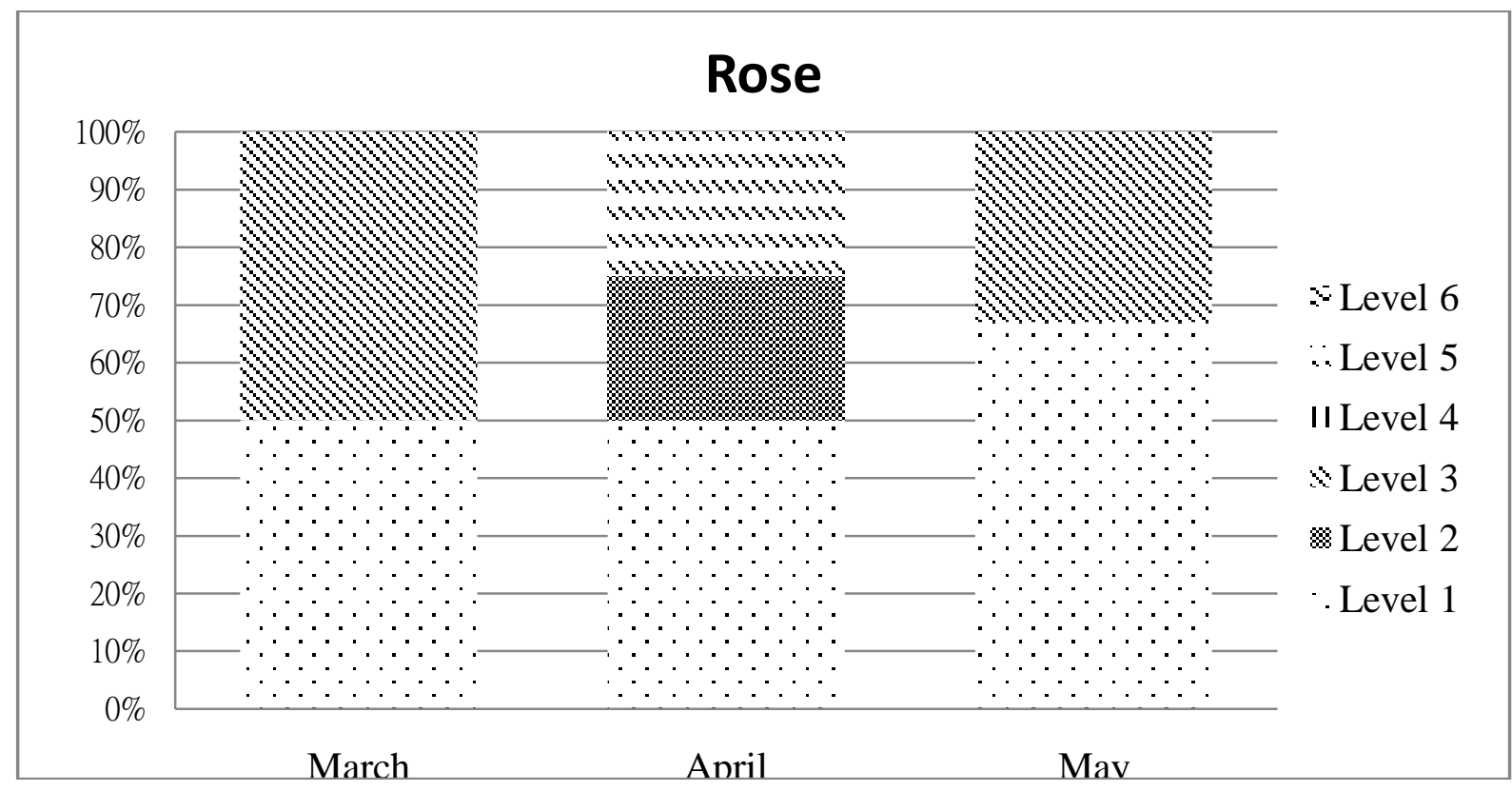

March 19: $\quad$ What did Batty see in the field? (Level 1)

What will you do if you come across a fearful animal when you're alone? (Level 3)

April 30: How do you feel if your parents are going to force you to do what you don't like? (Level 5)

Will you ask Dexter for publishing book if you were Jane? (Level 3)

What gift did Batty give to Jeffrey? (Level 1)

May 08: $\quad$ What did Jeffrey do to Hound? (Level 1)

What happened between Jane and Skye? (Level 1)

Will you run away if you were Jeffrey? (Level 3)

Chart 2. Sample Questions Raised by Julianfrom the Kindle Group 


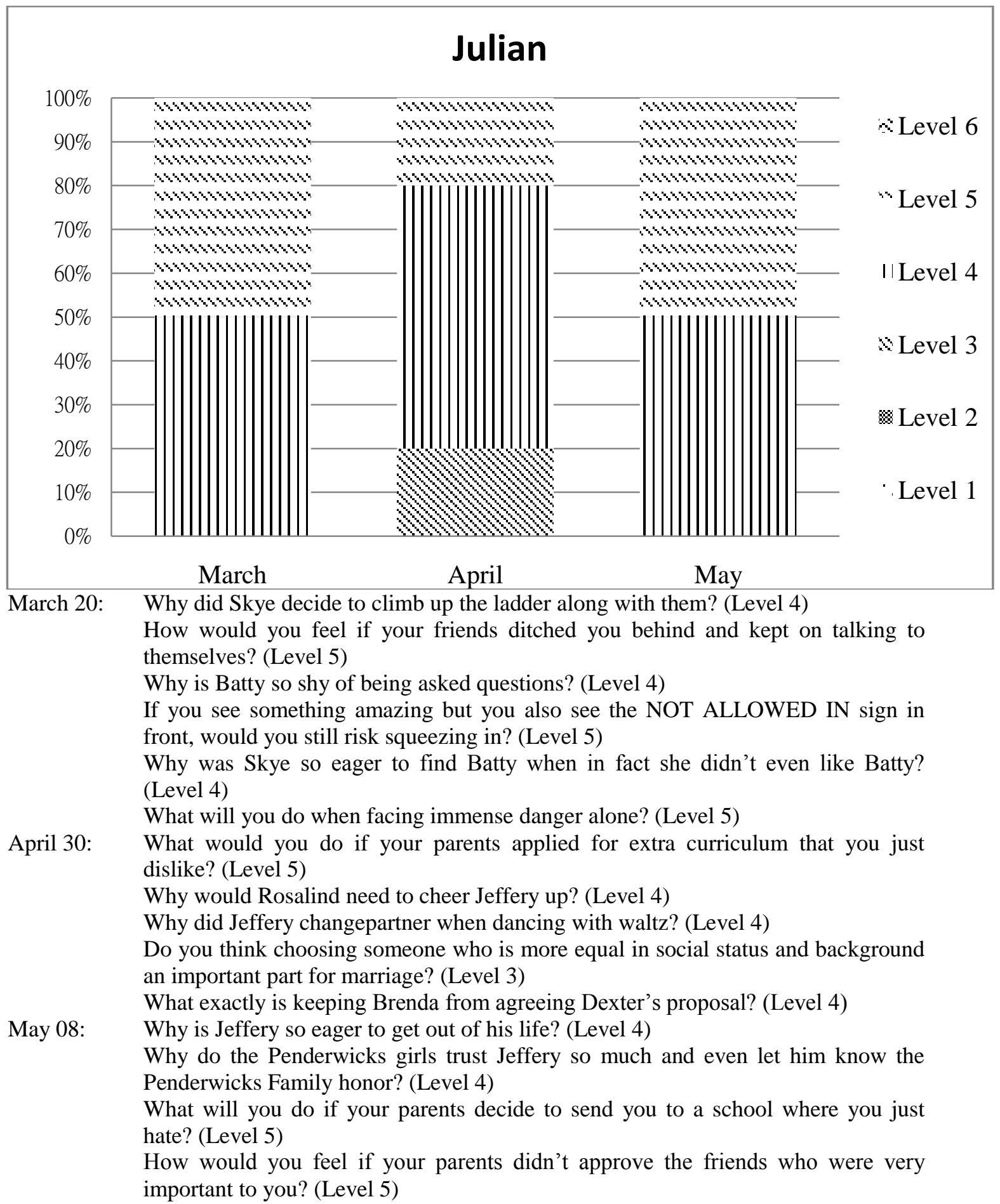

Participants in the hard copy group tended to raise more lower-order thinking questions, such as information questions. The results suggest that Kindle-mediated reading may be correlated with the participants' capacity to raise higher-order thinking questions. Allowing EFL readers the fluidity to move back and forth (Hartman et al., 2010) via Kindle may explain why the participants in the Kindle group raised more higher-order thinking questions which are commonly seen as an indication of critical thinking ability. Because the Kindle readers can decide reading sequences, they may think of themselves as active meaning-makers rather than a passive recipient of text. This finding is congruent with Charney's (1994) viewpoint that hypertext reading changes the way people process information. Another explanation may be due to the Kindle participants' conscious decision-making during the reading process, which engages them in critical thinking. In other words, instead of following the standard page order, Kindle readers are free to decide what reading sequence they want to pursue and tend to monitor their reading progress to validate their decision making intentionally. 
McKnight (2000) stated that "the level of questions asked influences the depth of thinking that occurs" (p.39). Likely, the participants in the Kindle group raised higher-order thinking questions because their depth of thinking was greater than the hard-copy group. In the current study, the high-order thinking questions were more prevalent among Kindle readers, suggesting that Kindle-mediated reading may be beneficial in cultivating higher-order thinking questions.

\subsection{No significant difference was found in self-efficacy between the hard copy group and the Kindle group}

To investigate if there is any difference in the participants' reading self-efficacy, the Self-Efficacy Scale was given to the 45 students toward the end of the study. Only 43 students returned the questionnaire. An independent samples t-test was conducted to detect any potential difference. The results indicate that the Kindle group scored 73.42 and the hardcopy group 73.11 on average at the end of this project.

Table 2. Descriptive Statistics of Self-Efficacy between Hard-Copy and Kindle Group

\begin{tabular}{lllll}
\hline & Group & N & Mean & Std. Deviation \\
\hline Self-Efficacy & Hard Copy & 19 & 73.11 & 8.49 \\
& Kindle & 24 & 73.42 & 6.76 \\
\hline
\end{tabular}

Table 3. Independent Samples T-Test of the Self-Efficacy Scale

\begin{tabular}{lllllll}
\hline & $\mathrm{t}$ & df & $\begin{array}{l}\text { Sig. } \\
(2 \text { tailed })\end{array}$ & Mean Difference & \multicolumn{2}{l}{ Std. Error Difference } \\
\cline { 4 - 6 } & & 41 & .89 & -.31 & Lower & Upper \\
\hline $\begin{array}{l}\text { Hard Copy Group vs. } \\
\text { Kindle Group }\end{array}$ & -.134 & 49.01 & -58 \\
\hline
\end{tabular}

Table 3 shows that no significant difference in reading self-efficacy was found between the two groups. This finding coincides with the data gathered from the open-ended survey. The analyses of the responses to the open-ended survey questions about self-efficacy indicate that integrating Kindle-mediated electronic reading didn't promote the participants' sense of confidence in tackling English novels, which is manifested in the following two themes.First, half of the entire cohort didn't consider themselves skillful in reading English novels. There is no significant difference in the percentage regarding their responses between the two groups. Table 4 shows that for the hard copy group, 35\% of them agreed they were skillful in reading English novels, 50\% disagree with the statement, and 11\% remained neutral. The main reasons accounting for their skillfulness include being able to get the gist of the chapter and knowing when to look up the words to confirm their comprehension. For instance, participant M said that "I think I was good at reading these novels because I could picture the image as the plot went on. Also, when I discussed the plot with my friends, I could tell them what happened in a particular chapter." Participant A responded that "I think yes, because I can know what it is talking about with finding out words in the dictionary." As for those who hold a neutral position, they believe the contents of the novel dictate how skillful they can be. The responses from the kindle group show that $35 \%$ of the participants considered they were skillful in

Table 4. Percentages of Responses Regarding Skillfulness in Reading English Novels

\begin{tabular}{lccc}
\hline \multicolumn{4}{l}{ You have finished reading 8 novels this school year. Will you say you are skillful in reading English novels now? } \\
\hline Groups & Yes & No & It depends \\
Hard-Copy & $35 \%$ & $50 \%$ & $11 \%$ \\
Kindle & $35 \%$ & $47 \%$ & $18 \%$ \\
\hline
\end{tabular}

reading these novels, $47 \%$ did not consider so and $18 \%$ stated that it depends on thecontent of the novel. The most frequently mentioned reason relates to the use of strategies while reading. For example, participant V stated, "I use selfmotivating and pacing strategies to form a habit of reading novel at least 40 minutes per day."Second, when asked if they would claim themselves to be a good reader in general, the hard copy responded positively, whereas the Kindle group negatively. This finding resonates with the insignificant difference derived from the independent samples t-test. More than half of thehard-copy participants deemed themselves to be good readers while the kindle group participants didn't show such optimistic self-appraisal. The most frequent reason cited by the hard copy participants has to do with their ability to understand the novel content and to connect it to their life experiences. 
For instance, participant A described, "I think I am a good reader

Table 5. Percentages of Responses Regarding Being a Good Reader in General

\begin{tabular}{lcll}
\hline \multicolumn{2}{l}{ Are you a good reader in general? } & & \\
\hline Groups & Yes & No & It depends \\
Hard-Copy & $56 \%$ & $39 \%$ & $6 \%$ \\
Kindle & $39 \%$ & $33 \%$ & $28 \%$ \\
\hline
\end{tabular}

cuz [because] I can understand the plot and what the author wants to telling [tell] us from the story." Different from the hard copy group, only $39 \%$ of the Kindle group participants regarded themselves as good readers while more than onethird denounced the title of being a good reader. For those who considered themselves to be a good reader, they attribute their ability to build a connection with the novel and the metacognitive strategy of monitoring their comprehension as the leading causes. Participant P, for example, explained that "I think I am a good reader. If I couldn't understand the content for the first time, I would stop and try to figure out before I continue to read. In short, I monitor my comprehension constantly." Participant V said that "I think I am a good reader. I have a passion for reading, and I connect my feelings to the characters in the novel." However, for one-third of those who did not perceive themselves to be good readers, slow reading speed, interrupted reading behavior, and procrastinated reading schedule contributed to the negative self-appraisal.

The current results on self-efficacy suggest that learner control provided by Kindle did not help EFL readers boost their self-efficacy in reading. The independent sample t-test of the self-efficacy scale shows that there was no significant difference in self-efficacy in reading between the two groups. Additionally, according to the open-ended survey, nearly $1 / 3$ of the participants in the Kindle group regarded themselves as poor readers. Lawless \& Brown (1997) proposed that self-efficacy can be improved by giving learners control over their learning environment. Moreover, Chou \& Liu (2005) stated that hypermedia could provide learners a sense of control, which in turn will affect their level of confidence and motivation. Nevertheless, the current results from the independent sample t-test of self-efficacy scale and the majority of Kindle participants' negative identity as good readers show no such positive effects of hypertext reading on reader self-efficacy (Lawless \& Brown; 1997, Chou \& Liu, 2005). It's speculated that if the pre and posttest design were implemented with both groups, the results might have been different.

\section{Pedagogical Implications and Conclusion}

The current study found that the high-order thinking questions were more prevalent among Kindle readers, suggesting that Kindle-mediated reading may have helped EFL learners raised more analytic, synthetic, and evaluative questions. Echoing McKnight's (2000) assertion, the higher-order thinking questions raised by the Kindle group may reflect the development of their critical thinking. That is to say, Kindle-mediated reading may provide students with a new way of reading English and exploring their mental universe to make connections and value. Given the overflowing information the EFL learners come to in contact with, cultivating their critical thinking is far more imperative than before. The current results suggest that Kindle-mediated electronic reading has a positive influence on developing their higherorder thinking. It remains inconclusive as to whether integrating the popular technologies into the reading course will boost self-efficacy in reading among EFL readers. The findings from the current study indicate there is no significant difference in reading-related self-efficacy between the hard copy and Kindle group, which contradicts the claimed effect of learner control on self-efficacy. For the future study of utilizing the Kindle or other electronic reading devices with the EIL readers, it is desirable to investigate its effects on reading comprehension. After all, any reputable reading program should be able to yield positive results in boosting reading comprehension. The findings of this study may be limited to the context where the study took place; nevertheless, its implications for classroom practices may be extended to other settings. The researcher expects that the teachers who endeavor to adopt electronic readers, such as the Kindle, do so with their unique needs and students in mind. The current findings resonant with an emerging body of research maintain that learning is socially constructed within the new literacies. Students count on one another for direction, support, and construction of knowledge within the technology-rich environment, and so should educators. By helping each other, sharing ideas, and supporting future research, teachers can provide their students with literacy futures they deserve.

\section{References}

Atkinson, D. (1997). A Critical Approach to Critical Thinking in TESOL. TESOL Quarterly, 31, 71-90.

Bandura, A. (1991). Social cognitive theory of moral thought and action. In W. M. Kurtines\& J. L. Gewirtz (Eds.), Handbook of moral behavior and development (Vol. 1, pp. 45-103). Hillsdale, NJ: Erlbaum. 
Bandura, A. (1994). Self-efficacy. In V. S. Ramachaudran (Ed.), Encyclopedia of human behavior (Vol. 4, pp. 71-81). New York: Academic Press. (Reprinted in H. Friedman [Ed.], Encyclopedia of mental health. San Diego: Academic Press, 1998).

Brabazon, T. (2007). The university of Google: education in the (post) information age. Burlington, VT: Ashgate.

Brown, E. (1997). Effectively teaching critical thinking skills to high school students. Seton Hall University. (ERIC Document Reproduction ServiceNo.ED429850)

Browning, C., Halvorsen, J., \& Ahlquist, D. (1996). Shared inquiry fosters critical thinking skills in EFL students. In Hokkai Gakuen University, Kokugakuin Junior College, and The Great Books Foundation, On JALT 96: Crossing Boarders. Tokyo: Japan Association for Language Teaching.

Charney, D. (1994). The impact of hypertext on processes of reading and writing. Literacy and Computers. New York: MLA.

Chou, S. W., \& Liu, C. H. (2005). Learning effectiveness in a web-based virtual learningenvironment: A learner control perspective. Journal of Computer Assisted Learning, 21,65-76.

Davidson, B. W. (1998). Comments on Dwight Atkinson's "A critical approach to critical thinking in TESOL": A case for critical thinking in the English language classroom. TESOL Quarterly, 32, 119-123.

Davidson, B. W., \& Dunham, R. L. (1996). Assessing EFL student progress in critical thinking with the Ennis-Weir critical thinking essay test. HokuseiGakuen University. (ERIC Document Reproduction Service No.ED403302)

Day, R. (2003). Teaching critical thinking and discussion. JALT Journal. Retrieved from http://www.jaltpublications.org/tlt/articles/2003/07/day

Hartman, D. K., Morsink, P. M., \& Zheng, J. (2010). From print to pixels: The evolution ofcognitive conceptions of reading comprehension. In E. A. Baker (Ed.), MultiplePerspectives on New Literacies Research and Instruction (pp. 1-45). New York, NY:Guilford.

Jong de, T. and Hulst van der, A. (2002) The effects of graphical overviews on knowledge acquisition in hypertext. Journal of Computer Assisted Learning, 18 (2), 219-231.

Kamada, L. D. (1996). Comparing cultures through critical thinking: Development and interpretation of meaningful observations. Hirosaki University. On JALT 96: Crossing Borders. Tokyo: Japan Association for Language Teaching.

Kassem, C. L. (2005). A Conceptual Model for the Design and Delivery of Explicit Thinking Skills Instruction. The Twelfth International Conference on Learning, Granada, Spain.

Landow, G. P. (1992). Hypertext: the convergence of technology and contemporary critical theory. Johns Hopkins University Press, Baltimore, MD.

Lawless, K. A., \& Brown, S. W. (1997). Multimedia learning environments: Issues of learner control and navigation. Kluwer Academic Publishers, 25, 117-131.

Lodewijks, H. (1982). Self-regulated versus teacher-provided sequencing of information in learning from text. In A. Flammer \& W. Kintsch (Eds.). Amsterdam: North-Holland.

Long, C. J. (2000). Teaching critical thinking in Asian EFL contexts: Theoretical issues and practical applications. Sophia University.

MacKnight, C. B. (2000). Teaching critical thinking through online discussions. Educause Quarterly, 4, 38-41.

Merrill, M. D. (1984). What is learner control? (ERIC Document Reproduction Service No. ED 298905.$)$

Patrick, J. J. (1986). Critical thinking in the social studies. (ERIC Document

Reproduction Service No.ED272432)

Patterson, S. R. (1993). Promoting critical thinking skills for fourth grade students through the use of children's books. Nova University. (ERIC Document Reproduction Service No.ED384441)

Scheja, M. (2006). Delayed understanding and staying in phase: students' perceptions of their study situation. Higher Education, 52(3), 421-445.

Shapiro, A.M., \&Niederhauser, D.S. (2004). Learning from hypertext: research issues and findings. In D. H. Jonassen (Ed.), Handbook of research on educational communications and technology (2nd ed, pp. 605-620). Mahwah, NJ: Erlbaum.

Tillman, Y. R. (1994). Improving critical thinking skills in second graders through instruction and teacher-led discussion groups. Nova Southeastern University. (ERIC Document Reproduction Service No. ED 373907). 


\section{Appendix A}

\section{Self-Efficacy Scale}

Instruction: This questionnaire is a series of statements about your personal reading ability. Each statement represents a commonly held belief. Read each statement and decide to what extent it describes you. There is no right or wrong answers. You will probably agree with some of the statements and disagree with others. Please indicate your own personal feelings about each statement below by marking the letter that best describes your attitude or feeling. Please be very truthful and describe yourself as you really are, not as you would like to be. Thank you!

\begin{tabular}{|c|c|c|c|c|c|}
\hline & & Strongly Agree & Agree & Disagree & Strongly Disagree \\
\hline \multicolumn{6}{|c|}{ I. $\quad$ Self-Evaluation about Reading Behavior } \\
\hline 1. & If someone interrupts me, I can still find ways to stick to my goals. & & & & \\
\hline 2. & $\begin{array}{l}\text { It is easy for me to stick to my aims and accomplish my reading } \\
\text { goals. }\end{array}$ & & & & \\
\hline 3. & When I set up a reading goal, I often achieve it. & & & & \\
\hline 4. & $\begin{array}{l}\text { I am confident that I could read efficiently with unexpected events.?? } \\
\text { Unclear }\end{array}$ & & & & \\
\hline 5. & I know how to handle unforeseen situations when I read the novel. & & & & \\
\hline \multicolumn{6}{|c|}{ II. $\quad$ Self-Evaluation about Reading Ability } \\
\hline 6. & I am confident that I can understand $80 \%$ of the novel. & & & & \\
\hline 7. & I have enough of a vocabulary that I can read smoothly. & & & & \\
\hline 8. & I can understand the main idea of a story by myself. & & & & \\
\hline 9. & If the novel seems uninteresting to me, I will not even try to read it. & & & & \\
\hline 10. & I easily give up reading when I encounter unknown vocabulary. & & & & \\
\hline 11. & I can solve most problems if I put forward the necessary effort. & & & & \\
\hline 12. & I am confident that I can retell what I read to my friends. & & & & \\
\hline 13. & I easily quit when I don't understand the story. & & & & \\
\hline 14. & It is a pain to read in English. & & & & \\
\hline \multicolumn{6}{|c|}{ III. $\quad$ Self-Evaluation about Reading Willingness } \\
\hline 15. & I like to read English books. & & & & \\
\hline 16. & I enjoy the challenge I encounter when I read in English. & & & & \\
\hline 17. & Reading English books makes me feel a sense of achievement. & & & & \\
\hline 18. & $\begin{array}{l}\text { When reading an interesting English story, I will be engaged in the } \\
\text { plots. }\end{array}$ & & & & \\
\hline 19. & I am afraid of reading English books. & & & & \\
\hline 20. & I will read English books voluntarily. & & & & \\
\hline \multicolumn{6}{|c|}{ IV. $\quad$ Self-Evaluation about Reading Skill } \\
\hline 21. & $\begin{array}{l}\text { If I cannot understand the novel, I can guess the plot from the } \\
\text { context. }\end{array}$ & & & & \\
\hline 22. & $\begin{array}{l}\text { I am good at using strategies (scanning, skinning, etc...) to read the } \\
\text { novel. }\end{array}$ & & & & \\
\hline 23. & I am good at reading English books. & & & & \\
\hline 24. & Overall, I am a good reader. & & & & \\
\hline 25. & I believe I will keep making progress in reading English. & & & & \\
\hline
\end{tabular}

